\title{
Forewing Shape Variability Between Sexes and Across Populations of the Rice Bug, Leptocorisa varicornis Fabricius (1803) Using Geometric Morphometrics
}

\author{
Clifford P. Bendoy, Magdalene Mae L. Del Socorro, \\ Marie Rosellyn C. Enguito, Charity May L. Dacayana

\begin{abstract}
Natural Science Department, College of Arts and Sciences, Misamis University, Ozamiz City, Philippines

Corresponding email: cliffordbendoy@yahoo.com
\end{abstract}

\begin{abstract}
Leptocorisa varicornis (F.) (1803) rice bug is a serious pest of rice. Misidentification of this pest had led to non-effective management strategies resulting to possible emergence of insecticide resistance. Proper identification of this species is necessary in developing effective management strategies against this pest, and correct identification needs accurate examination of the insect's morphology. Geometric morphometrics (GM) statistically analyzes shape variability allowing better understanding of the nature and variability of the insect in relation to the evolvability of characters and its possible implications to adaptability of the organism. This study made use of GM to determine forewing shape variability between sexes and across populations of L. varicornis (F.) from selected localities in Northern Mindanao, Philippines. Exploratory results initially showed that variations between sexes were generally characterized by differences in overall shape of forewing, apex and wing base. Variations across populations were associated largely with differences in overall forewing shape, contour of inner margin, and shape of wing base. Series of confirmatory tests obtained highly significant results, which all confirmed presence of intersexual and interpopulation variations in L. varicornis. Environmental stressors like seasonal cropping, flood and application of pesticides might influence differences in forewings of rice bugs since rice bugs have to fly to long distance after cropping or change location when existing habitat conditions are no longer suitable for their survival. Thorough understanding of the biological basis of the observed variations is essential for the effective control against this species.
\end{abstract}

Keywords: environmental stressors, insect, insect's morphology, intersexual variations, pest 


\section{Introduction}

Loss of rice production because of pests is one of the most important things that have been given attention (Supriatna, 2003). The major measure to control insect pests depends upon the application of chemical pesticides. According to Heinrichs and Barrion (2004), in order to develop effective and comprehensive pest management strategies, it is essential to identify properly and to understand the biology and ecology of insect pests. Correct identification of a newly detected pest or disease vector is of utmost importance because the scientific name of an organism is the key to all known information about its morphology, its behavior and life history, and its potential threat to human welfare (Schauff, 1986).

However, insecticidal control has led to several problems in insect pest management like insecticide resistance in pests because insect populations have a wide range of genetic variability that maximizes their fitness in the presence of genetic diversity of host plants. Distinct populations of agronomic pest sometimes differ only on minute phenotypic characters. Sometimes, these characters are often seen associated with virulence and may represent stable characters with genetic bases (Torres et al., 2010). In the case of L. varicornis (Fabricius), this species is frequently misidentified in literatures as L. acuta (Thunberg), L. acuta (Stahl), or L. oratorius (Fabricius) owing to close resemblances among these species (Jahn et al., 2004).

Existing studies on rice bugs emphasize on life-history, control, and ecology rather than morphology. Most of the morphometric studies on some Leptocorisa spp. are solely based on the linear measurements of the size of the individuals sampled (Querino et al., 2002). One comprehensive way of addressing these problems requires innovation and cooperation within the scientific community which in this study is through the use of landmark-based GM which provides considerable added informed inferences (Torres et al., 2010) on the biology of the pest by quantifying and identifying the nature of morphological variations of a biological form (Losos, 1990; Ricklefs \& Miles, 1994; Caley et al., 1995; Conde-Padin et al., 2007). 
GM involves statistical analysis of shape and is found to be an indispensable technique in the identification of species (Torres et al., 2010). Generally, this new method allows better assessment of morphologic characteristics (Hood, 2000).

It is easier to identify the relationship between morphology and ecology by quantifying morphological variation, (Losos, 1990; Ricklefs \& Miles, 1994) and thus make additional informed inferences on the evolution of pest organisms (Adams, 1999). Thorough understanding of the biological basis of the observed morphological variation is necessary for the effective formulation of management strategies for populations of Leptocorisa species.

This study is primarily in search for significant phenotypic forewing shape differences in the rice bug L. varicornis (F.) using a series of geometric morphometric tests. Particularly, this research aims to describe and quantify forewing shape variability between sexes (sexual dimorphism) and across populations or locations of L. varicornis (F.) collected from Lala, Lanao del Norte and Bacolod, Ozamis City.

\section{Materials and Methods}

Collection of rice bug samples on rice paddies was done by using sweep nets. Different geographical locations or municipalities in Northern Mindanao, Philippines were chosen as the sampling sites of the rice bug, Leptocorisa varicornis (F.) which included Barangay Bacolod, Ozamis City, Misamis Occidental and the municipality of Lala, Lanao del Norte and (Figure 1). Voucher rice bug specimens were placed in a bottle filled with $10 \%$ ethanol immediately after collection to preserve the samples properly. Specimens were then brought to the laboratory for the dissection of different desired body parts to be studied. Only adult L. varicornis (F.) rice bugs were subjected to dissection (Figure 2). Prior to dissection, each rice bug specimen collected was sorted according to sex. 


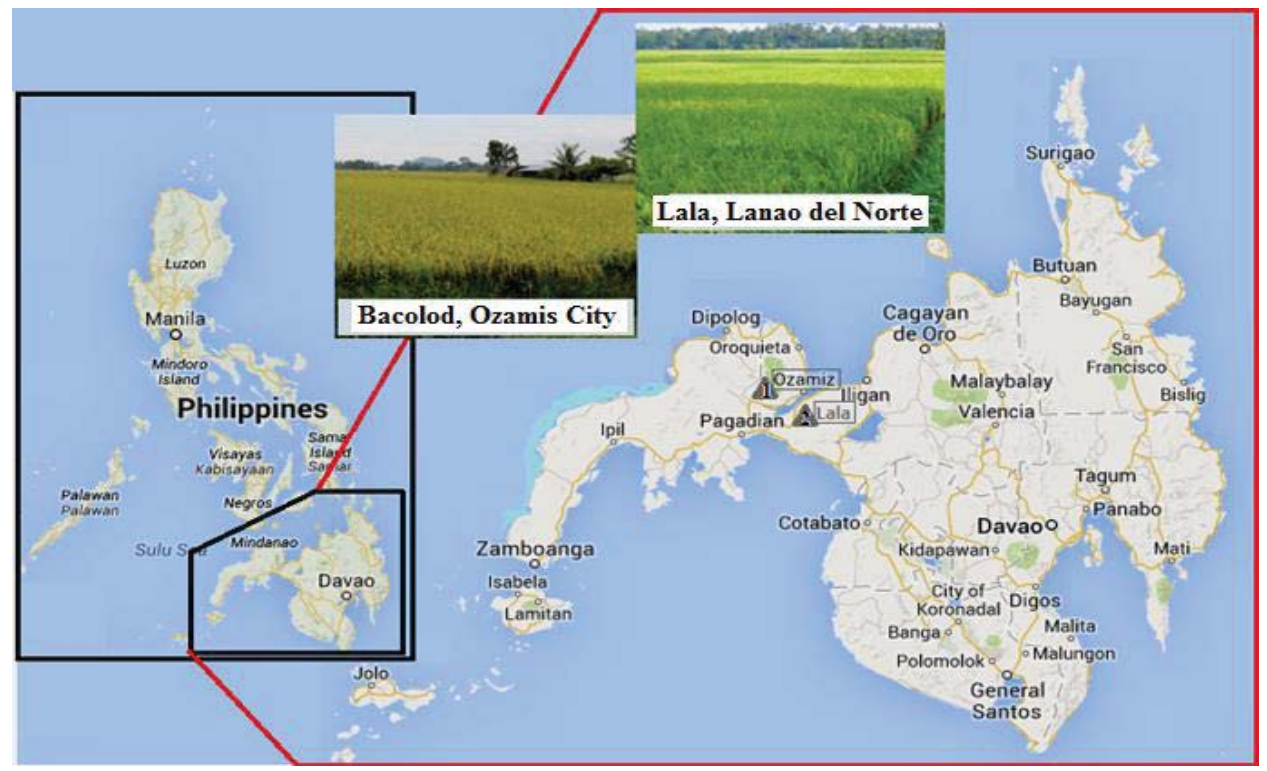

Figure 1. Topographical display of the map of selected sampling sites (filled markers) of Leptocorisa varicornis (1-Bacolod, Ozamiz City, Misamis Occidental and 2-Lala, Lanao del Norte) (Source: http://maps. google.com.ph).

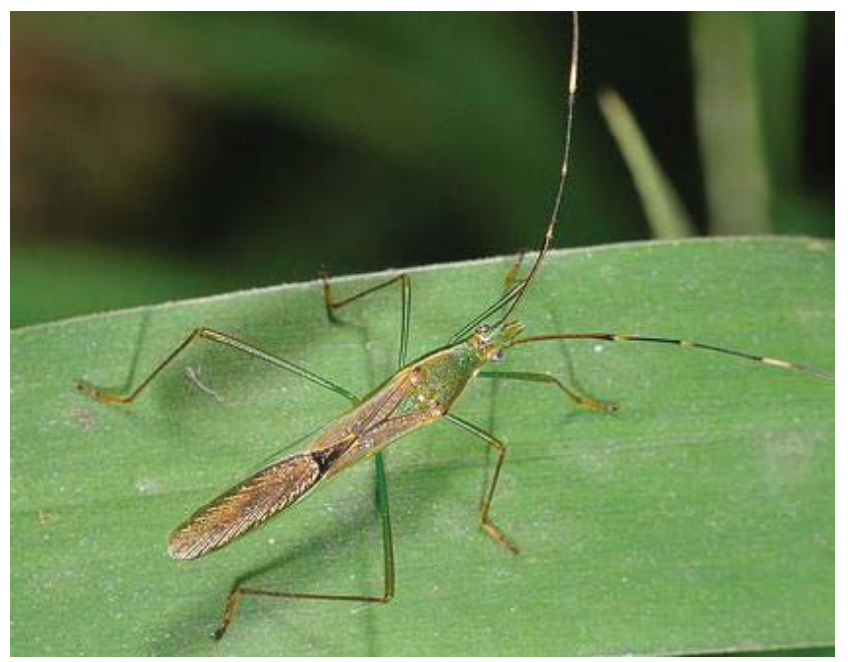

Figure 2. Typical appearance of a Leptocorisa varicornis (F.) rice bug (Photo (C) Cleany Lee). 
Sexing of L. varicornis (F.) involved examination of the genital plate - an external structure located at the last or eleventh segment of abdomen. Female rice bugs have nearly pointed genital plates while males have blunt genital end plate (Figure 3). Dissection of the samples involved removal of the forewing of $L$. varicornis $(\mathrm{F}$.) using forceps and dissecting needle. Wing samples were mounted on a glass slide and scanned under 1200-dpi resolution.

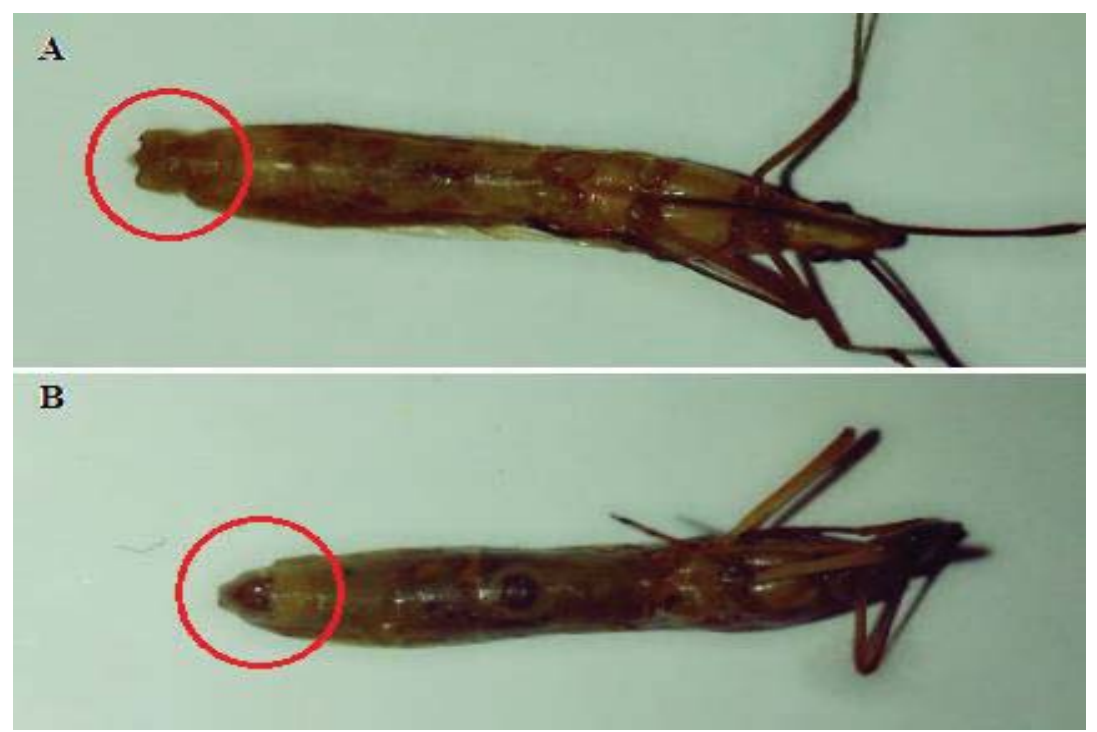

Figure 3. Photograph of a typical male (A) and female (B) rice paddy bug (ventral view). Females exhibit pointed genital end plate while males generally have blunt genital end plate.

Using tpsDig ver. 2.10 program (Rohlf, 2006), images of the rice bug forewings were digitized. Thirty-five anatomical landmark points were defined along the outline of the forewing obtaining a total of one hundred ninety-five (195) curve points (Figure 4). Table 1 summarizes the location of each landmark point. Three (3) replicates of these landmarks were used to minimize the measurement error (Dvorak et al., 2006). These defined anatomical landmarks and/or curve points configured to Cartesian coordinates were subjected to Generalized Orthogonal Least Square process, a method of alignment (Rohlf, 1990; Rohlf \& Slice, 1990) and 
superimposition that minimizes differences between forms and separates the shape from the size component of the biological form (Zelditch et al., 2012).
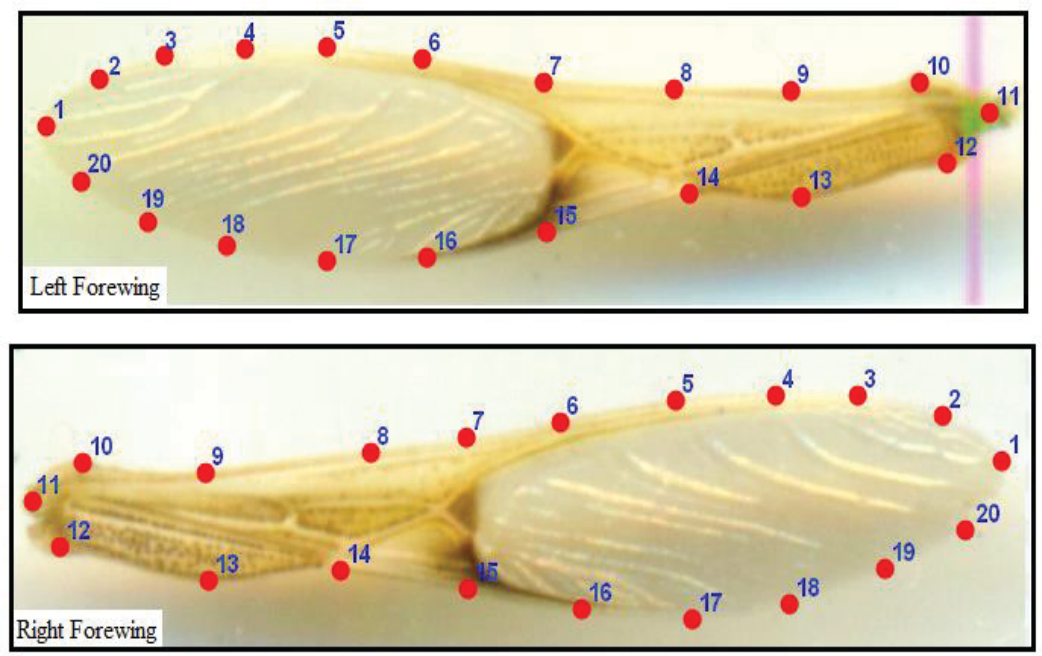

Figure 4. Arrangement and location of the 35 landmark points along the contour of the left and right forewing of $L$. varicornis (F.).

Table 1. Location and classification of 20 anatomical landmarks digitized on forewing shape of rice bugs $L$. varicornis $(\mathbf{F}$.).

\begin{tabular}{ll}
\hline Landmark Number & Location \\
\hline 1 & apical margin \\
$2,3,4,5,6$ & costal margin of the membrane \\
$7,8,9$ & costal margin of the corium \\
$10,11,12$ & base of the forewing \\
$13,14,15$ & inner margin, outer margin of clavus \\
$16,17,18,19,20$ & anal margin of the membrane \\
\hline \hline
\end{tabular}




\section{Data Analysis}

\section{Relative Warp Analysis}

Following superimposition of anatomical landmarks, the data were subjected to Relative Warp Analysis using the tpsRelw ver. 1.45 program (Rohlf, 2007). This method was used to detect subtle shape differences of the forewing of L. varicornis (F.). A consensus configuration of the forewing shape was obtained using this analysis, and relative warp scores were computed. The obtained consensus configuration was then used as the reference configuration by which variations in other shape transformations were based. Each relative warp provides two deformed shape spaces or grids; the negatively deviated (+ end of the relative $\mathrm{x}$-axis) shape space and positively deviated (- end of the relative $\mathrm{x}$-axis) shape space. Relative distribution of the variances projected in a box plot provides a decisive criterion in selecting which of the two deviations best assumes the form (with respect to the mean shape) that contributes largely to the total forewing shape variability. Relative warp scores that are greater than $5 \%$ are considerably significant. The computed relative warp scores were then regarded as the basis for all succeeding statistical analyses.

\section{Thin-plate Spline Analysis}

Patterns of forewing shape variability between sexes and among populations of the rice bug, L. varicornis (F.) were analyzed using the thin-plate spline technique. Shape variability shown as deformations and differences in shape among the specimens were expressed as a bending energy matrix. The eigenvectors of the bending energy matrix are known as principal warps. The eigenvalue, associated to each principal warp, is inversely related to the spatial scale of shape change so that large eigenvalues describe small-scale deformations, whereas small eigenvalues indicate large-scale deformations. These deformation grids were then used to represent graphically the patterns of shape variation among the landmarks. The tpsSplin ver. 1.20 program (Rohlf, 2004) was used for this particular analysis. 


\section{Multivariate Analysis of Variance (MANOVA)}

Multivariate Analysis of Variance (MANOVA) was done using PAST software (Harper \& Ryan, 2001) to test the significance of the observed variations. MANOVA is a form of multivariate measure where a multivariate F value (Wilk's lambda) is obtained based on a comparison of the error variance/covariance matrix and the effect variance/covariance matrix. This Wilk's lambda would determine the relationship between several variables (Torres et al., 2010). A small (close to 0) value of Wilk's' lambda means that the groups are well separated, and a large (close to 1) value of Wilk's lambda means that the groups are poorly separated. A large Pillai trace value suggests that mean shapes between sexes contributed largely to the total observed variations.

\section{Discriminant Function Analysis (DFA)}

Discriminant Function Analysis, another method of multivariate analysis was used in order to determine among-group shape differences of L. varicornis $(\mathrm{F}$.) forewing between sexes and among populations. DFA is a standard method for visually confirming or rejecting the hypothesis that two species are morphologically distinct. A zero cut-off point (the midpoint between the means of the discriminant scores of the two groups) classifies groups into two (Harper \& Ryan, 2001). More particularly, DFA was used to assign unclassified specimens in a group to previously defined groups. Percentage of correct classification equal or higher than the cut-off percentage score which is 75 is considered to be significant which indicates that the two data sets being tested are distinct. This type of statistical analysis was done using PAST software.

Figure 5 below shows the series of methods and statistical tests employed to evaluate and determine variability in forewing shape between sexes and across populations of $L$. varicornis (F.) rice bugs. 
Forewing Shape Variability Between Sexes and Across Populations of the Rice Bug, Leptocorisa varicornis Fabricius (1803)

Using Geometric Morphometrics

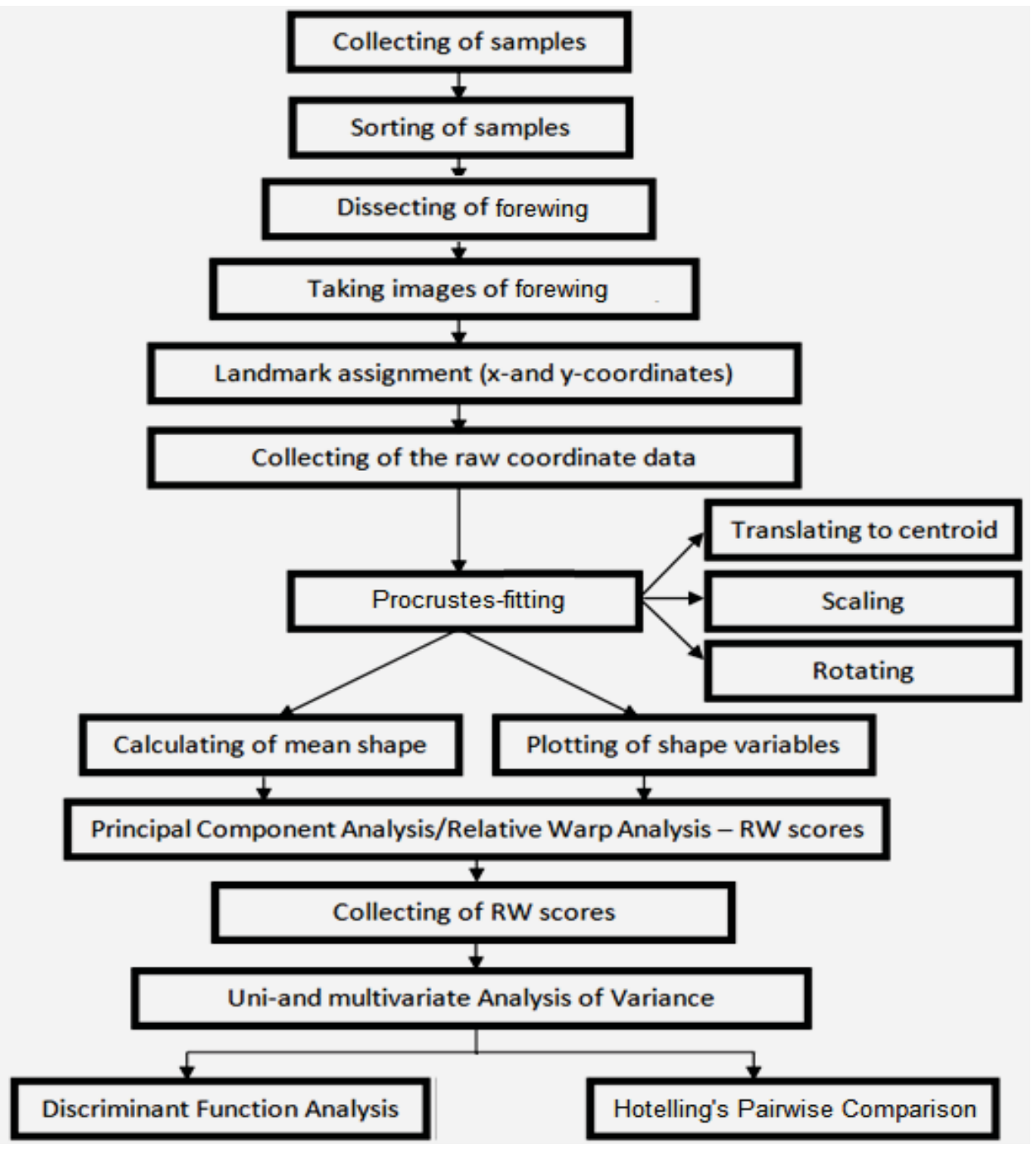

Figure 5. Summary of the procedures used to determine forewing shape variability between sexes and across populations of the rice bug, L.varicornis (Fabricius). 


\section{Results and Discussion}

Differences in forewing shape morphology between sexes and among populations of L. varicornis (F.) were quantified and determined using anatomical landmark points that were localized on the contour of the left and right forewing which generated coordinates and scores that were subjected to several geometric morphometric tests.

Intersexual shape variabilities in the left and right forewing of rice bugs collected from Bacolod are shown in Figures 6 and 7 respectively. Variabilities between sexes in the left forewing were characterized by differences in the overall shape and in the shape or position of inner margin which all accounted for $41.13 \%$ of the total variances, and differences in the shape of the wing base (17.10\% of the total variance) and wing apex $(13.36 \%$ of the total variance). With respect to right forewing shape, male and female rice bugs differed highly from each other in terms of the shape of the apex and on the outer angle of the wing which contributed to $31.20 \%$ of all computed variances. Minor variations between sexes were attributed to the differences in the shape of the inner margin $(27.36 \%)$ and in the overall forewing shape and shape of wing base (13.49\%).

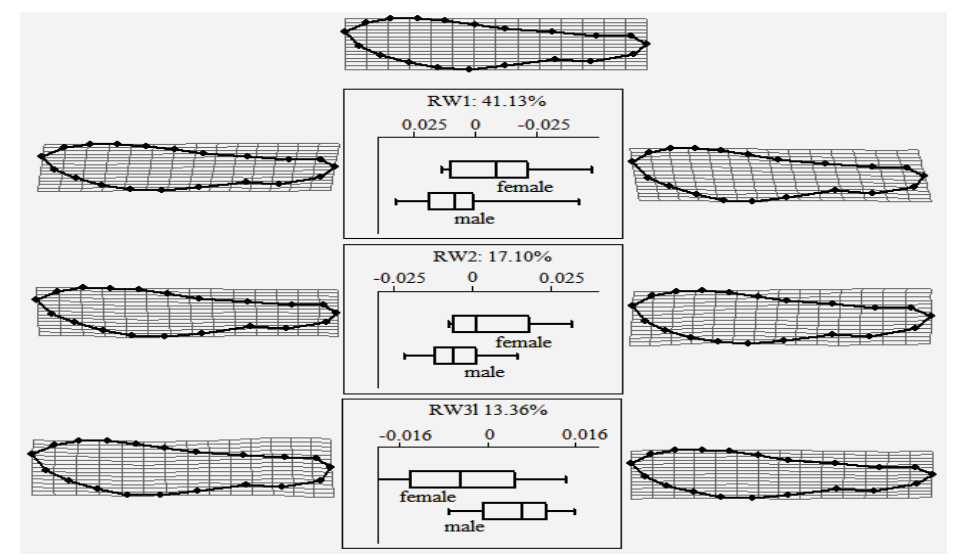

Figure 6. Results of the Relative Warp Analysis for pooled male and female $L$. varicornis $(\mathrm{F}$.) rice bugs collected from Bacolod showing left forewing shape variability between sexes as expressed by the first three highly significant relative warps. 


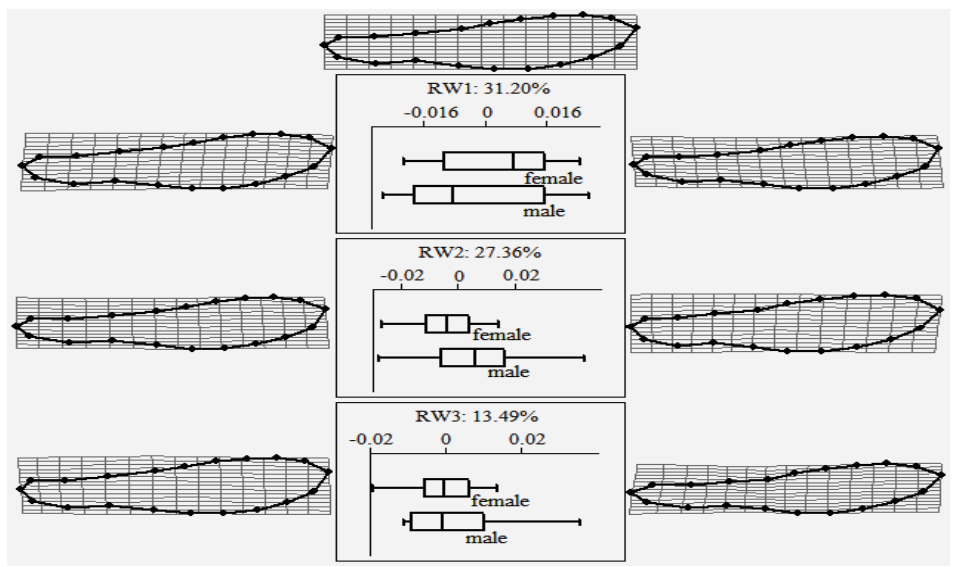

Figure 7. Results of the Relative Warp Analysis for pooled male and female L.varicornis $(\mathbf{F}$.) rice bugs collected from Bacolod showing right forewing shape variability between sexes as expressed by the first three highly significant relative warps.

Forewing shape variabilities between sexes in left and right forewing of rice bugs collected from Lala are presented in Figures 8 and 9 respectively. Variances in left forewing between sexes were largely attributed to the differences in the overall forewing shape and wing base $(34.58 \%$ of the total variances) with slight differences on the shape of the inner margin $(19.00 \%)$ and contour of outer margin (12.70\%). Relatively, right forewing variabilities relatively were associated with differences in the shape of the wing base (48.23\%), wing apex (12.22\%), and in the overall shape (10.24\%).

Assessing the observed localized variabilities between sexes with regards to left and right forewings, male rice bugs collected from Bacolod generally have tapered wing apex, pointed wing base and a slender left forewing while females have blunt wing apex, broad wing base and a broad left forewing. Meanwhile, right forewing of male rice bugs collected from the same area exhibit a broad wing shape with broad wing apex, pointed wing base and a more oblique inner margin. Females on the other hand, have slender wing shape with sharp wing apex, pointed wing base and a less oblique inner margin. 


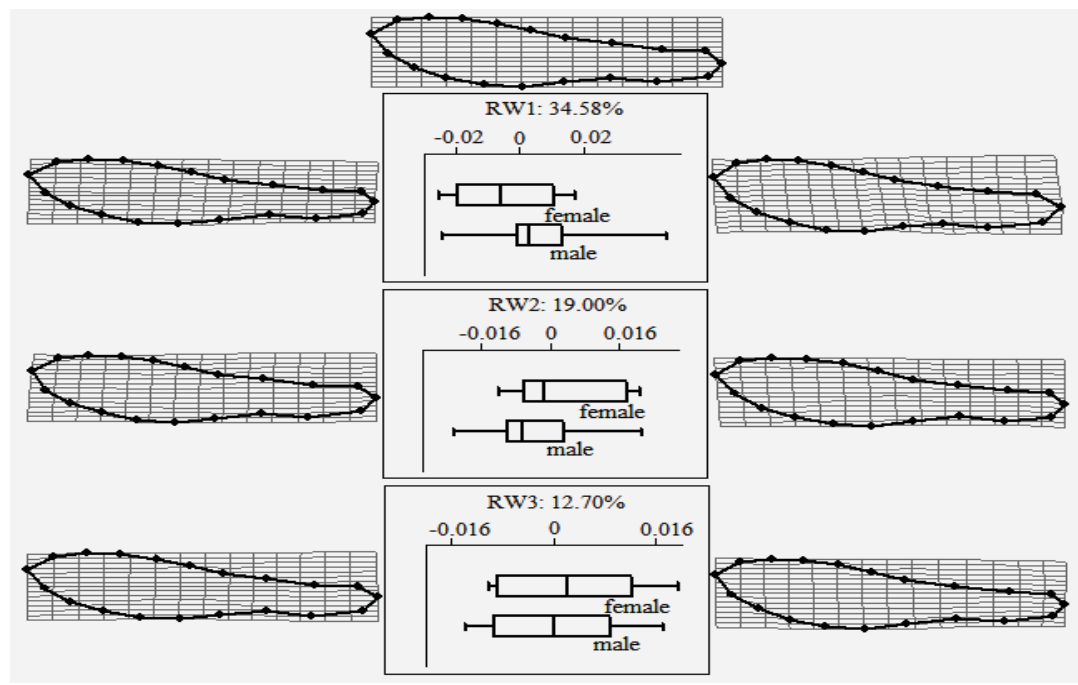

Figure 8. Results of the Relative Warp Analysis for pooled male and female L.varicornis (F.) rice bugs collected from Lala showing left forewing shapevariability between sexes as expressed by the first three highly significant relative warps.

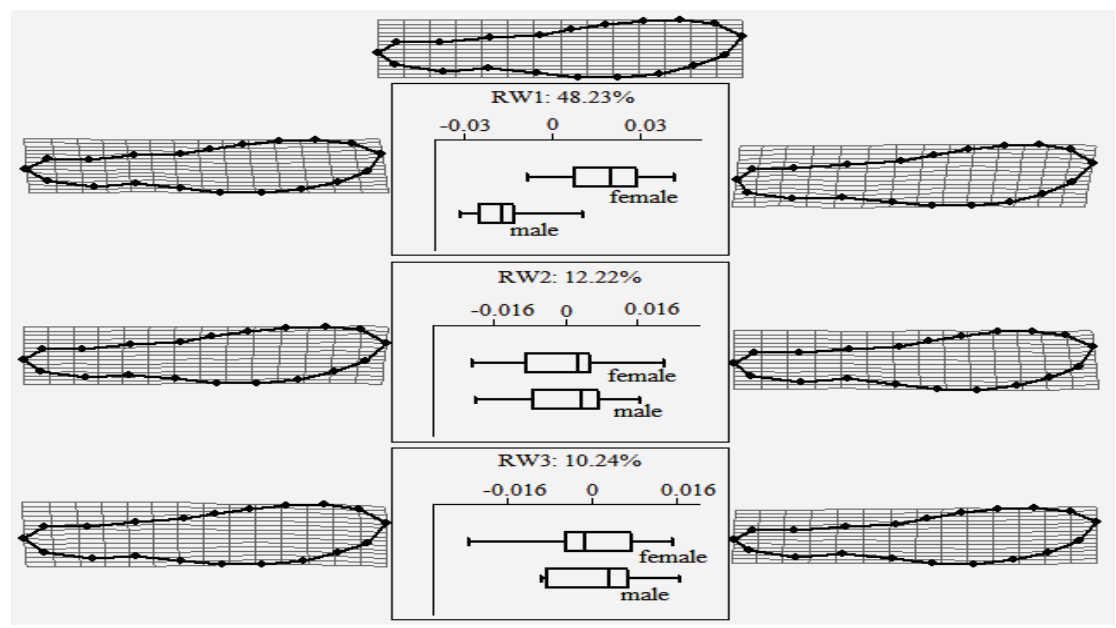

Figure 9. Results of the Relative Warp Analysis for pooled male and female L. varicornis $(\mathbf{F}$.) rice bugs collected from Lala showing right forewing shape variability between sexes as expressed by the first three highly significant relative warps. 
Intersexual forewing shape variabilities of rice bugs collected in Lala were associated with males exhibiting wide wing base, less skewed inner margin, wide costal or outer margin and a broad left forewing while females display narrow wing base, greatly skewed inner margin, narrow costal margin, and narrow left forewing. On account of right forewing variability, male rice bugs display broad wing shape with narrow wing base and sharp wing apex while females have slender forewing with broad wing base and sharp wing apex.

The abovementioned observed localized shape variations in the left and right forewing of L. varicornis (F.) were based on the first three highest relative warps. Since relative warp analysis was used only in exploring significant patterns of forewing shape variability through deformation plates or grids, all the initial exploratory variabilities observed were confirmed or substantiated using several confirmatory tests - MANOVA, discriminant function analysis and $\mathrm{F}$ and $\mathrm{t}$ tests. Initial results showed that sexual dimorphism or difference between sexes of $L$. varicornis (F.) existed both in Bacolod and Lala on the basis of variation in the forewing shape.

Separate $\mathrm{F}$ and $\mathrm{t}$ tests were done on the left and right forewings of the rice bug L. varicornis (F.) to confirm the observed forewing shape variation between sexes obtained using the previous test (Table 2). F and $\mathrm{t}$ tests provide $\mathrm{p}$ (same) values, which indicate how close the individual variances and the mean variances are to one another correspondingly. Among all data sets, only left forewing of the rice bugs collected from Bacolod showed a significant result on F test (RW3 in particular). This indicates that individual forewing shape variances of the rice bug samples in Bacolod essentially contribute to the observed variability between sexes of rice bugs in the area. Results of t test showed significant forewing shape variability (with respect to mean shape) between sexes of $L$. varicornis (F.) rice bugs both in Lala and Bacolod.

Significant $\mathrm{p}$ (same) values of both $\mathrm{F}$ and t tests initially confirmed and validated the previous result obtained via relative warp analysis. It can be deduced that sexual dimorphism exists in rice bugs collected from Bacolod and Lala whereby variations are attributed to differences in the mean variances of the forewing shape. 
Table 2. Localized intersexual variations of the left and right forewing of the rice bugs, $L$. varicornis $(\mathbf{F}$.) using $\mathbf{F}$ and $\mathbf{t}$ tests.

\begin{tabular}{rccccccc}
\hline \hline Character & Relative Warp & $\mathrm{F}$ & $\mathrm{P}$ & Remark & $\mathrm{t}$ & $\mathrm{p}$ & Remark \\
\hline Left Forewing, Bacolod & & & & & & \\
RW1 (41.13\%) & 1.11 & 0.844 & insignificant & 2.54 & 0.017 & significant \\
RW2 (17.10\%) & 1.88 & 0.250 & insignificant & 2.61 & 0.014 & significant \\
RW3 (13.36\%) & 3.54 & 0.024 & significant & -2.62 & 0.015 & significant \\
Left Forewing, Lala & & & & & & \\
RW1 (34.58\%) & 1.06 & 0.910 & insignificant & 2.05 & 0.050 & significant \\
RW2 (19.00\%) & 1.02 & 0.976 & insignificant & -1.43 & 0.164 & insignificant \\
RW3 (12.70\%) & 1.01 & 0.979 & insignificant & 0.72 & 0.477 & insignificant \\
Right Forewing, Bacolod & & & & & & \\
RW1 (31.20\%) & 1.40 & 0.541 & insignificant & 0.93 & 0.362 & insignificant \\
RW2 (27.36\%) & 1.83 & 0.270 & insignificant & -2.06 & 0.049 & significant \\
RW3 (13.49\%) & 1.76 & 0.301 & insignificant & -0.26 & 0.793 & insignificant \\
Right Forewing, Lala & & & & & & \\
RW1 (48.23\%) & 1.99 & 0.210 & insignificant & 7.91 & 0.001 & significant \\
RW2 (12.22\%) & 1.28 & 0.654 & insignificant & -0.14 & 0.891 & insignificant \\
RW3 (10.24\%) & 1.65 & 0.357 & insignificant & -0.58 & 0.568 & insignificant \\
\hline \hline
\end{tabular}

MANOVA was performed to further validate the result of t-test. Table 3 shows the variability between sexes in forewing shape expressed as deviations of the difference of mean variances of forewing samples. Results showed that male and female rice bugs in Bacolod differed morphologically in their left forewing - on account of highly significant Hotelling's results, small Wilk's lambda, and large Pillai trace. Apart from this, there was also significant difference (in the right forewing) between sexes of rice bugs coming from Lala as depicted by highly significant values/results obtained in MANOVA. 
Table 3. Mean variances in the left and right forewing between sexes of the rice bugs, L. varicornis $(\mathbf{F}$.) using MANOVA.

\begin{tabular}{ccccc}
\hline \hline Character & Hotelling's p (same) & Remark & Wilk's lambda & $\begin{array}{c}\text { Pillai } \\
\text { trace }\end{array}$ \\
\hline Left Forewing, Bacolod & 0.00004 & significant & 0.4204 & 0.5796 \\
Left Forewing, Lala & 0.09078 & insignificant & 0.7832 & 0.2168 \\
Right Forewing, Bacolod & 0.19168 & insignificant & 0.8361 & 0.1639 \\
Right Forewing, Lala & 0.0000005 & significant & 0.2967 & 0.7033 \\
\hline \hline
\end{tabular}

Results strongly confirm and indicate that sexual dimorphism exists between sexes of $L$. varicornis (F.) as to forewing shape. The male and female rice bug groups are highly distinguished from one another on this basis.

Another approach in determining sexual dimorphism (and to warrant as well the previous result on Pillai trace test) is through Discriminant Function Analysis which reclassifies two groups of rice bug samples to its previously defined groups thereby determining equality in the means of the two groups. The higher the percentage of group reclassification, the greater is the morphological differentiation between male and female rice bugs. Table 4 shows the reclassification of rice bug samples to its predicted group based on forewing shape.

Results showed that all data sets remarkably obtained significant (above the cut-off score, $75 \%$ ) group reclassification counts or percentages. This suggests that male and female rice bugs in both Bacolod and Lala are morphologically distinct with regards to forewing shape. High percentage of reclassification counts in left forewing (Bacolod) and right forewing (Lala) data sets support the results in MANOVA. 
Table 4. Reclassification count of male and female $L$. varicornis $(\mathbf{F}$.) rice bugs based on the discriminant scores of the left and right forewing shapes.

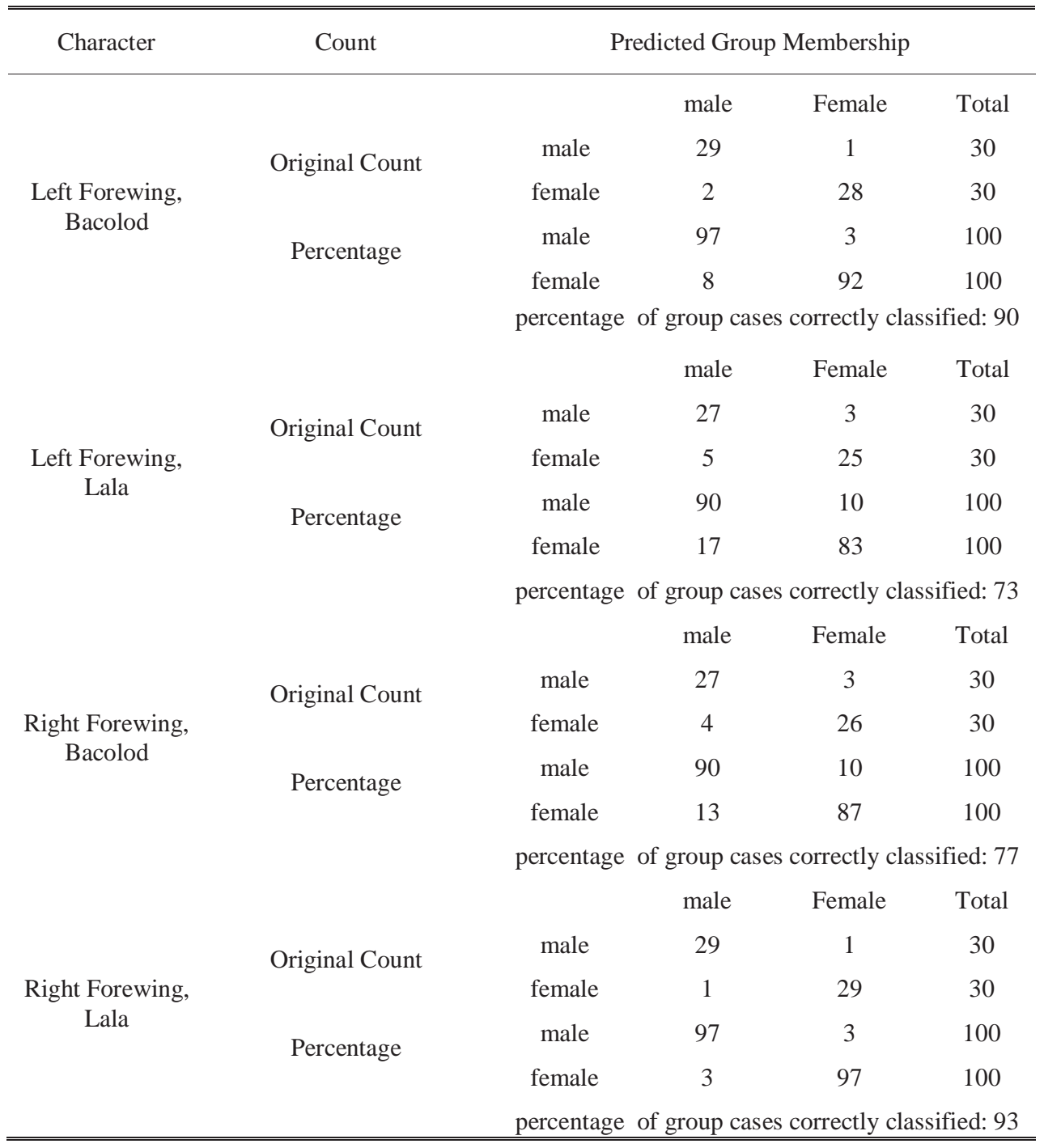

Variability in left and right forewing across populations of rice bug, L. varicornis is shown in succeeding figures. Patterns of forewing shape variability across populations in the left forewing of female rice bugs are associated with disparities in the shape of the wing base which accounts for the highest relative warp $(40.91 \%)$, followed with minor disparities in the shape of the inner margin $(21.36 \%)$ and costal margin (11.98\%) as shown in 
Forewing Shape Variability Between Sexes and Across Populations of the Rice Bug, Leptocorisa varicornis Fabricius (1803)

Using Geometric Morphometrics
C.P. Bendoy, M.M.L. Del Socorro, M.R.C. Enguito \& C.M.L. Dacayama

Figure 10. With respect to right forewing shape of female rice bugs, variabilities across populations are also associated with disparities in the shape of the wing base ( $43.17 \%$ of the total variances) and in the costal margin (11.33\%), with slight variation in the shape of the wing apex $(16.45 \%)$ as shown in Figure 11.

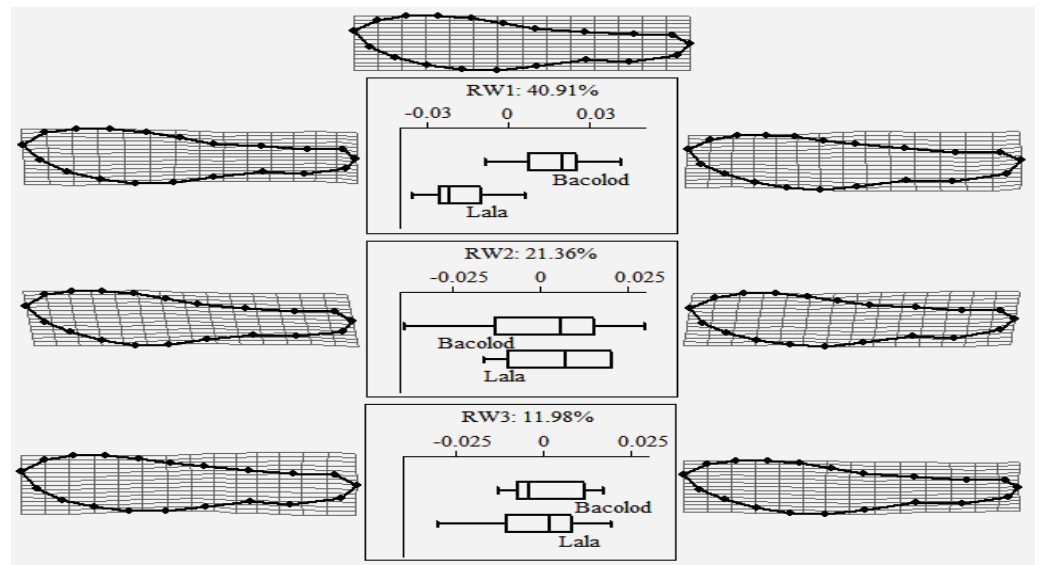

Figure 10. Results of the Relative Warp Analysis of the female L. varicornis (F.) rice bugs showing left forewing shape variability across different locations as expressed by the first three highly significant relative warps.

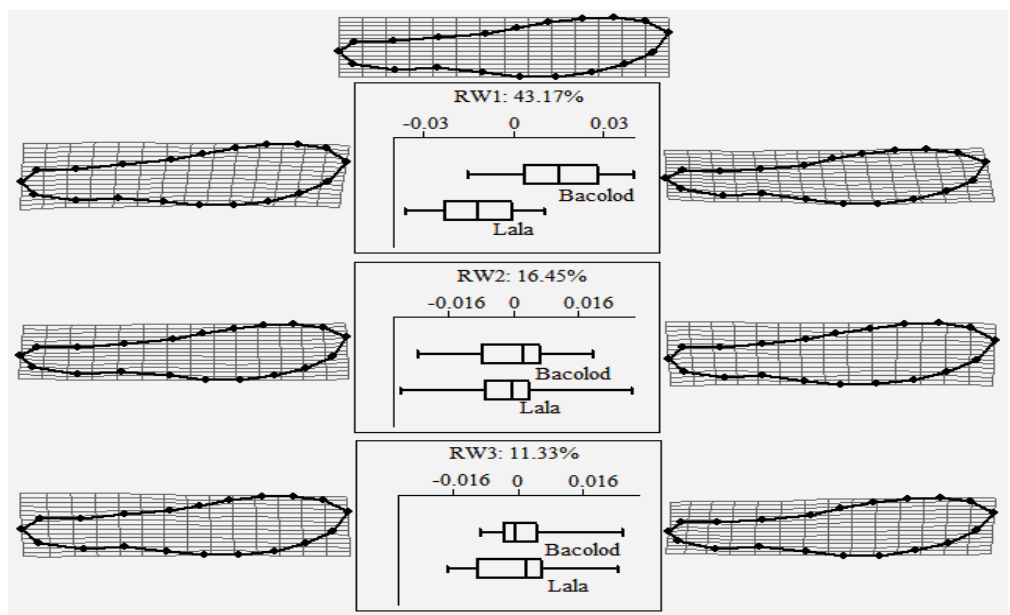

Figure 11. Results of the Relative Warp Analysis of the female $L$. varicornis (F.) rice bugs showing right forewing shape variability across different locations as expressed by the first three highly significant relative warps. 
Interpopulation variability in male rice bugs was detected in both left and right forewings. Major variations across populations (41.15\% of the total variances) in left forewing are attributed to the differences in overall shape of the wing. Slight variations in the shape of the wing base $(20.48 \%)$ and inner margin $(12.97 \%)$ are also detected (Figure 12). With respect to right forewing, rice bugs across locations highly vary in terms of differences in the shape of inner margin $(27.93 \%)$, wing base $(20.85 \%)$ and in the overall wing shape $(17.21 \%)$ as shown in Figure 13.

Based on the results, differences across populations in left and right forewing shape were observed in both female and male rice bugs. It was found out that left forewing shape differs across populations in female rice bugs as evidenced by Bacolod rice bugs having broad wing base, greatly skewed inner margin, and a narrow costal margin, while Lala female rice bugs bear slender wing base, less skewed inner margin and wide or long upper margin. With respect to variability in the right forewing, Bacolod female rice bugs exhibit pointed and slender wing base, blunt apex, and narrow upper margin, while Lala female rice bugs display broad wing base, similarly a blunt apex and a wide upper margin.

Comparing with the female rice bugs, the male rice bugs from Bacolod have slender left forewing with sharp and slender wing base and more oblique inner margin. Lala rice bugs in contrast have broad left forewing with broad wing base and less oblique inner margin. In terms of right forewing disparities, Bacolod male rice bugs bear forewing with more oblique inner margin, broad wing base and a broad forewing while Lala rice bugs display forewings with less oblique inner margin, slender and sharp wing base and a slender forewing.

Observed results initially explored significant patterns of localized forewing shape variations across populations of L. varicornis (F.) rice bugs expressed through the deformation grids or plates. Results obtained were validated using series of confirmatory tests. Meanwhile, initial results of Relative Warp Analysis showed that interpopulation variability exists in the forewing of the rice bug L. varicornis (F.). 
Forewing Shape Variability Between Sexes and Across Populations of the Rice Bug, Leptocorisa varicornis Fabricius (1803) Using Geometric Morphometrics

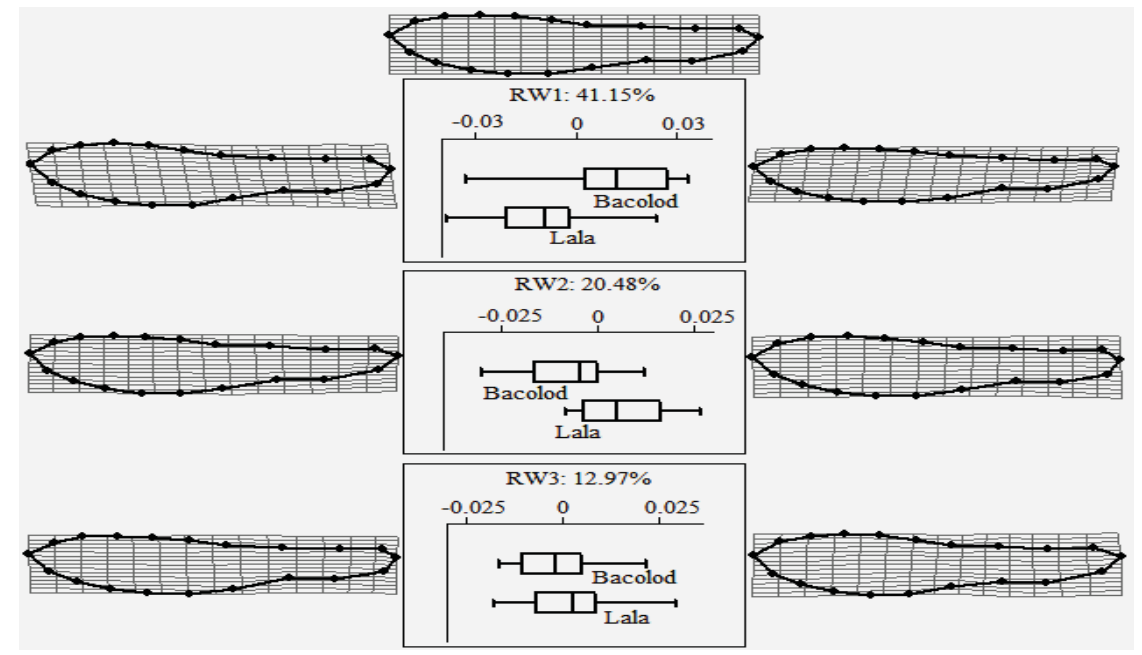

Figure 12. Results of the Relative Warp Analysis of the male L. varicornis (F.) ricebugs showing left forewing shape variability across different locations as expressed by the first three highly significant relative warps.

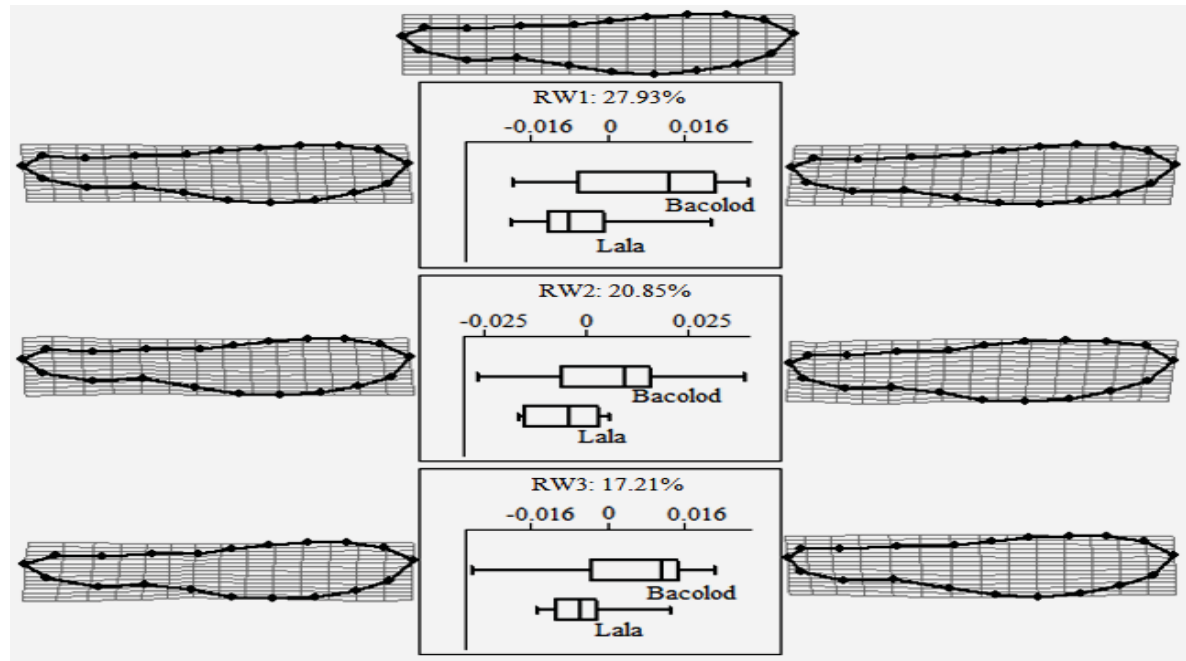

Figure 13. Results of the Relative Warp Analysis of the male L. varicornis (F.) ricebugs showing right forewing shape variability across different locations as expressed by the first three highly significant relative warps. 
$F$ and $t$ tests were performed to confirm the observed variations in the forewing across populations of $L$. varicornis (F.). Among all data sets analyzed, only right forewing male data set showed significant result in $F$ test (Table 5). This suggests that the observed interpopulation variations in male rice bugs (with respect to individual right forewing variances) are considered to be significant. This means that the rice bugs from Bacolod and Lala are morphologically distinct from each other (description of RW2 and RW3). Remarkably, results in $t$-test showed significant disparity in the mean variance of all data sets. This implies that differences in the mean forewing shape contribute largely to the variability of rice bugs across populations. Significant results on both $F$ and $t$ tests further imply that interpopulation variation exists in L. varicornis (F.) and that variations can be detected in both left and right forewing.

Table 5. Variations in the left and right forewing among populations of the rice bugs, $L$. varicornis $(\mathbf{F}$.) using $\mathbf{F}$ and $\mathbf{t}$ tests.

\begin{tabular}{|c|c|c|c|c|c|c|c|}
\hline Character & Relative Warp & $\mathrm{F}$ & $\mathrm{p}$ & Remark & $\mathrm{T}$ & $\mathrm{p}$ & Remark \\
\hline \multicolumn{8}{|c|}{ Left Forewing, female } \\
\hline & RW1 $(40.91 \%)$ & 1.15 & 0.794 & insignificant & 7.64 & $2.5 \mathrm{E}-8$ & significant \\
\hline & RW2 (21.36\%) & 1.52 & 0.445 & insignificant & -0.63 & 0.530 & insignificant \\
\hline & RW3 (11.98\%) & 1.78 & 0.293 & insignificant & 0.04 & 0.964 & insignificant \\
\hline \multicolumn{8}{|c|}{ Left Forewing, male } \\
\hline & RW1 (41.15\%) & 1.19 & 0.746 & insignificant & 3.87 & $5.8 \mathrm{E}-4$ & significant \\
\hline & RW2 (20.48\%) & 1.15 & 0.794 & insignificant & -3.40 & 0.002 & significant \\
\hline & RW3 (12.97\%) & 1.29 & 0.644 & insignificant & -1.07 & 0.295 & significant \\
\hline \multicolumn{8}{|c|}{ Right Forewing, female } \\
\hline & RW1 (43.17\%) & 1.43 & 0.510 & insignificant & 5.07 & $2.3 \mathrm{E}-5$ & significant \\
\hline & RW2 (17.10\%) & 1.27 & 0.663 & insignificant & -0.28 & 0.779 & insignificant \\
\hline & RW3 (13.36\%) & 1.75 & 0.305 & insignificant & 0.46 & 0.648 & insignificant \\
\hline \multicolumn{8}{|c|}{ Right Forewing, male } \\
\hline & RW1 (27.93\%) & 2.89 & 0.057 & insignificant & 2.58 & 0.015 & significant \\
\hline & RW2 (20.85\%) & 3.80 & 0.018 & significant & 2.42 & 0.022 & significant \\
\hline & RW3 (17.21\%) & 3.75 & 0.019 & significant & 2.96 & 0.006 & significant \\
\hline
\end{tabular}


Results of $t$-test were further validated by MANOVA. Table 6 shows how varied are the mean forewing shape of rice bugs across populations. All data sets obtained extremely low values in Hotelling's, closer to 0 Wilk's lambda, and near 1 Pillai trace. These suggest that Bacolod and Lala rice bug groups are largely separated (distinct from each other morphologically) and that the two groups can be distinguished in terms of the variability in the mean shape of their forewing.

\section{Table 6. Mean variances in the left and right forewing among populations of the rice bugs, $L$. varicornis (F.) using MANOVA.}

\begin{tabular}{ccccc}
\hline \multicolumn{1}{c}{ Character } & Hotelling's p(same) & Remark & Wilk's lambda & Pillai trace \\
\hline Left Forewing, female & 0.0000014 & significant & 0.3233 & 0.6767 \\
Left Forewing, male & 0.0000013 & significant & 0.3200 & 0.6800 \\
Right Forewing, female & 0.0004850 & significant & 0.5105 & 0.4895 \\
Right Forewing, male & 0.0000200 & significant & 0.0353 & 0.6032 \\
\hline \hline
\end{tabular}

The use of Discriminant Function Analysis determines how two populations of rice bugs are closely or largely separated from each other. Table 7 shows significant (higher than 70\%) reclassification count of all data sets which indicates and validates as well that rice bugs from Bacolod are highly separated or distinct from those in Lala, based on morphological forewing shape character.

Insects have amazing adaptations that make each type unique and diverse. They are adapted for life in every environment imaginable (Keck, 2008). Most of the time, aspects of these adaptive phenotypes are functionally connected with ecological performance (Abrams, 1996). Some of the adaptations include the ability of an insect to fly which is the main function of insect's wings. Differences in the forewing morphology might be influenced by the insect's adaptive ability to various environmental conditions (Cui, 2010) particularly the rapid evolvability of the wings in response to artificial selection and geographic clines (Gilchrist et al., 2001; Kennington et al., 2003). Moreover, since forewing functions also (apart from flight function) for rice bug protection, one factor that may influence variability in rice bug forewing shape could be the necessity to guarantee shielding adaptations, making possible the wholeness of the delicate wing organs during inhabiting or visiting of the insect on whatever concealed habitats. 
Between sexes variation might be due to the fact that flight variation exists among rice bugs where it has been proven that females are stronger fliers compared to the males (Pathak \& Khan, 1994). According to Chakraborty et al. (1990), rice bugs also differ in qualitative features with varying geographic locations. Variability of the rice pest complex in different areas is associated with differences in cropping intensity, irrigation, variety, fertilizer, and pesticide use. Genetic factor could be a great factor of the observed variances.

Table 7. Reclassification count of $L$. varicornis $(\mathbf{F}$.) rice bugs across locations based on the discriminant scores of the left and right forewing shapes.

\begin{tabular}{|c|c|c|c|c|c|}
\hline Character & Count & \multicolumn{4}{|c|}{ Predicted Group Membership } \\
\hline \multirow{6}{*}{$\begin{array}{l}\text { Left Forewing, } \\
\text { female }\end{array}$} & \multirow{3}{*}{ Original Count } & & Bacolod & Lala & Total \\
\hline & & Bacolod & 29 & 1 & 30 \\
\hline & & Lala & 2 & 28 & 30 \\
\hline & \multirow{3}{*}{ Percentage } & Bacolod & & & 100 \\
\hline & & Lala & & & 100 \\
\hline & & percentage & of group ca & orrectly & fied: 90 \\
\hline \multirow{7}{*}{$\begin{array}{l}\text { Left Forewing, } \\
\text { male }\end{array}$} & \multirow{3}{*}{ Original Count } & & Bacolod & Lala & Total \\
\hline & & Bacolod & 29 & 1 & 30 \\
\hline & & Lala & 2 & 28 & 30 \\
\hline & \multirow{3}{*}{ Percentage } & Bacolod & & & 100 \\
\hline & & Lala & & & 100 \\
\hline & & percentage & of group ca & orrectly & fied: 90 \\
\hline & & & Bacolod & Lala & Total \\
\hline \multirow{6}{*}{$\begin{array}{c}\text { Right Forewing, } \\
\text { Female }\end{array}$} & \multirow{2}{*}{ Original Count } & Bacolod & 27 & 3 & 30 \\
\hline & & Lala & 3 & 27 & 30 \\
\hline & \multirow{4}{*}{ Percentage } & Bacolod & & & 100 \\
\hline & & Lala & & & 100 \\
\hline & & percentage & of group ca & orrectly & fied: 83 \\
\hline & & & Bacolod & Lala & Total \\
\hline \multirow{5}{*}{$\begin{array}{l}\text { Right Forewing, } \\
\text { male }\end{array}$} & \multirow{2}{*}{ Original Count } & Bacolod & 29 & 1 & 30 \\
\hline & & Lala & 1 & 29 & 30 \\
\hline & \multirow{2}{*}{ Percentage } & Bacolod & & & 100 \\
\hline & & Lala & & & 100 \\
\hline & & percentage & of group ca & orrectly & fied: 93 \\
\hline
\end{tabular}

At the species level, between-populations disparity and its correlation with environmental conditions is used to evaluate adaptation to local conditions (Loik \& Noble, 1993); and at further detail, morphological variability within a population can be related to the niche concept and dynamics (Pulliam, 1986) or to sexual selection (Møller, 1994). 


\section{Conclusion and Recommendations}

Patterns of forewing shape variability between sexes and across locations in the rice bug, L. varicornis (F.) were determined and quantified using landmark-based geometric morphometrics, a tool that provides better assessment of the variations of morphological characters. Relative warp analysis and series of multivariate statistical tests were employed to detect and confirm variations in the forewing.

Initial exploratory test using relative warp analysis showed that there exists intersexual and interpopulation shape variations in left and right forewings of $L$. varicornis (F.). Variations between sexes are generally characterized by differences in the overall shape of the forewing, shape of the apex, and shape of the wing base. Minor variations are detected that are mainly attributed to the disparities in shape or contour of the inner and outer margins. Variations across populations are associated largely with differences in the overall shape or contour of inner margin and in the shape of the wing base. Minor variations on disparities in the shape of contour of the outer margin were also observed.

Confirmatory tests using $\mathrm{F}$ and $\mathrm{t}$ tests, MANOVA and DFA obtained considerably significant and substantial results or values which all indicate that intersexual and inter population variations exist in $L$. varicornis (F.) and variations are evident in both left and right forewing.

Environmental stressors like seasonal cropping, flood and application of pesticides might influence morphological differences in the forewing of rice bugs since rice bugs have to fly to long distance after cropping or change location when existing habitat conditions are no longer suitable for their survival. Apart from this, forewings also function for rice bug protection, and with this, they vary with the requirement to manage or assure shielding adaptations, thereby protecting underlying delicate wing organs during the invasion of the insects on extreme locations. The results further imply that even slight variations in the shape of the forewing of the rice bug could be detected by geometric morphometric analysis. The consistency of geometric morphometrics in providing significant results indicates that it can become an important tool in taxonomic studies of the genus Leptocorisa and in studying morphological variations of other biological forms. A complete understanding and proper identification of the biological basis of the observed differences are elemental for the effective management of rice bugs pests. It is highly recommended that 
future studies take into consideration the inclusion of several anatomical structures of the rice bug such as head capsule which contains mouthparts used in sucking contents of the rice grains.

\section{Acknowledgment}

The senior author acknowledges Misamis University for the research grant.

\section{Literature Cited}

Abrams, P. A. (1996). Evolution and the consequences of species introductions and deletions. Ecology, 77(5), 1321-1328.

Adams, D. C. (1999). Methods for shape analysis of landmark data from articulated structures. Evolutionary Ecology Research, 1(8), 959-970.

Caley, K. J., Grahame, J., \& Mill, P. J. (1995). A geographically-based study of shell shape in small rough periwinkles. Hydrobiologia, 309(13), 181-193.

Chakraborty, D. P., Srivastava, P. C., Ghose, G. C., Maslen, N. R., Holt, J., \& Fowler, S. V. (1990). Rice pest abundance in Bihar and Orissa States, India. International Rice Research Newsletter, 15(4), 26-27.

Conde-Padín, P., Grahame, J. W., \& Rolán-Alvarez, E. (2007). Detecting shape differences in species of the Littorina saxatilis complex by morphometric analysis. Journal of Molluscan Studies, 73(2), 147-154.

Cui, B. (2010). Research progress on the wing and veins of Diptera Phoridae. International Journal of Biology, 2(2), 210.

Dvorak, V., Aytekin, A. M., Alten, B., Skarupova, S., Votypka, J., \& Volf, P. (2006). A comparison of the intraspecific variability of Phlebotomus sergenti Parrot, 1917 (Diptera: Psychodidae). Journal of Vector Ecology, 31(2), 229-238.

Gilchrist, G. W., Huey, R. B., \& Serra, L. (2001). Rapid evolution of wing size clines in Drosophila subobscura. Genetica, 112(1), 273-286. 
Harper, D. A. T., \& Ryan, P. D. (2001). PAST: paleontological statistics software package for education and data analysis. Palaeontol. Electronica, 4(1), 1-9.

Heinrichs, E. A. \& Barrion, A. T. (2004). Rice-feeding insects and selected natural enemies in West Africa: biology, ecology, identification. Los Baños (Philippines): International Rice Research Institute and Africa Rice Center

Hood, C. (2000). Geometric morphometric approaches to the study of sexual size dimorphism in mammals. Hystrix, the Italian Journal of Mammalogy, 11(1), 77-90.

Jahn, G. C., Domingo, I., Liberty, M., Almazan, P., \& Pacia, J. (2004). Effect of rice bug Leptocorisa oratorius (Hemiptera: Alydidae) on rice yield, grain quality, and seed viability. Journal of economic entomology, 97(6), 1923-1927.

Keck, M. (2008). Adaptations of insects. Texas AgriLife Extension. Texas A \& M System. Retrieved from https://insects.tamu.edu/youth/4h/ junior/adaptations.pdf

Kennington, W. J., Killeen, J. R., Goldstein, D. B., \& Partridge, L. (2003). Rapid laboratory evolution of adult wing area in Drosophila melanogaster in response to humidity. Evolution, 57(4), 932-936.

Loik, M. E., \& Nobel, P. S. (1993). Freezing tolerance and water relations of Opuntia fragilis from Canada and the United States. Ecology, 74(6), 1722-1732.

Losos, J. B. (1990). Ecomorphology, performance capability, and scaling of West Indian Anolis lizards: an evolutionary analysis. Ecological Monographs, 369-388.

Moller, A. P. (1994). Sexual selection and the barn swallow. Oxford: Oxford University Press. 
Pathak, M. D. \& Khan, Z. R. (1994). Insect pest of rice. Manila, Philippines: International Rice Research Institute

Pulliam, T. H. (1986). Artificial dissipation models for the Euler equations. AIAA journal, 24(12), 1931-1940.

Querino, R. B., Moraes, R. C. D., \& Zucchi, R. A. (2002). Relative warp analysis to study morphological variations in the genital capsule of Trichogramma pretiosum Riley (Hymenoptera: Trichogrammatidae). Neotropical Entomology, 31(2), 217-224.

Ricklefs, R. E., \& Miles, D. B. (1994). Ecological and evolutionary inferences from morphology: An ecological perspective. In P. C. Wainwright \& S. M. Reilley (Eds). Ecological morphology: integrative organismal biology (pp. 13-41). Chicago. University of Chicago Press.

Rohlf, F. J. (1990). An overview of image processing and analysis techniques for morphometrics. In Proceedings of the Michigan Morphometrics Workshop, 2, 37, a60.

Rohlf, F. J. (2006). tpsDig, version 2.10. Department of Ecology and Evolution, State University of New York, Stony Brook.

Rohlf, F. J. (2007). tpsRelw version 1.45. Department of Ecology and Evolution, State University of New York, Stony Brook.

Rohlf, F. J. (2004). tpsSpline thin-plate spline, version 1.20. Department of Ecology and Evolution, State University of New York at Stony Brook.

Rohlf, F. J., \& Slice, D. (1990). Extensions of the Procrustes method for the optimal superimposition of landmarks. Systematic Biology, 39(1), 40-59.

Schauff, M. E. (Ed.). (1986). Collecting and preserving insects and mites: techniques \& tools. Washington, D.C.: Systematic Entomology Laboratory, USDA. 
Forewing Shape Variability Between Sexes and Across Populations of the Rice Bug, Leptocorisa varicornis Fabricius (1803)

Using Geometric Morphometrics
C.P. Bendoy, M.M.L. Del Socorro, M.R.C. Enguito \& C.M.L. Dacayama

Supriatna, A. (2003). Integrated pest management and its implementation by rice farmer in Java. Jurnal Litbang Pertanian, 22(3), 109.

Torres, M. A. J., Lumansoc, J., \& Demayo, C. G. (2010). Variability in head shapes in three populations of the rice bug Leptoscorisa oratorius (Fabricius) (Hemiptera: Alydidae). Egyptian Academic Journal of Biological Sciences, 3(1), 173-184.

Zelditch, M. L., Swiderski, D. L., \& Sheets, H. D. (2012). Geometric morphometrics for biologists: A primer. London, UK: Academic Press. 